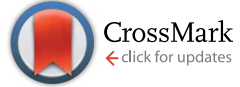

Cite this: RSC Adv., 2016, 6, 52122
Received 29th March 2016 Accepted 16th May 2016

DOI: 10.1039/c6ra08037e

www.rsc.org/advances

\section{Development of a cross-linked quaternized poly(styrene- $b$-isobutylene-b-styrene)/graphene oxide composite anion exchange membrane for direct alkaline methanol fuel cell application}

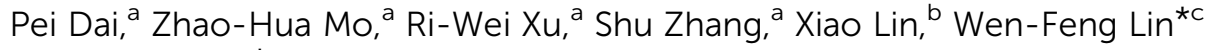 \\ and Yi-Xian $\mathrm{Wu}^{\star a}$
}

\begin{abstract}
A cross-linked quaternized poly(styrene- $b$-isobutylene-b-styrene)/graphene oxide composite anion exchange membrane has been prepared via intercalation of organo-modified graphene oxide (GOA), and characterized as a promising anion exchange membrane for direct alkaline methanol fuel cell application. In order to further increase the ionic conductivity of the composite membrane, quaternized GOA (GOAN) was introduced into QSIBS. Compared with the Nafion ${ }^{\circledR}$ membrane, the new anion exchange membranes show a comparable ionic conductivity $\left(1.95 \times 10^{-2} \mathrm{~S} \mathrm{~cm}^{-1}\right)$ but much lower methanol permeability $\left(1.7 \times 10^{-7} \mathrm{~cm}^{2} \mathrm{~s}^{-1}\right)$. The QSIBS/0047OAN-0.50 wt\% composite membrane has the highest selectivity, which is about 12 times higher than that of the Nafion 115 membrane. The promising performance is attributed to two factors: one is the barrier effect of the quaternized octadecylamine-functionalized graphene oxide sheets, which is unfavourable for methanol crossover; and the other is the presence of interconnected ionic transportation channels between the incorporated modified graphene oxide and polymer, which is favourable for ionic transport.
\end{abstract}

\section{Introduction}

The direct methanol fuel cell (DMFC) has attracted considerable attention as an alternative power source to batteries due to its high power density, high efficiency and instant refuelling. ${ }^{1}$ DMFC is expected to have a wide range of applications as a portable or mobile power source, for example replacing batteries for cellular phones or electric vehicles, with a potential to offer 10 times higher power densities than current lithiumion rechargeable batteries. ${ }^{2}$ The proton exchange membrane (PEM) running in acidic medium for the DMFC, Nafion ${ }^{\circledR}$, is the copolymer of perfluorinated vinyl ether comonomer with tetrafluoroethylene. ${ }^{3}$ Although it possesses a combination of high proton conductivity and excellent chemical stability under DMFC operating conditions, Nafion ${ }^{\circledR}$ has a big problem of high methanol permeability, which restricts its performance in the DMFC application. ${ }^{4}$ To reduce the methanol crossover, the modification of Nafion membranes has been investigated, including by forming a composite with a polymer having low methanol permeability, ${ }^{5-7}$ by doping with inorganic fillers ${ }^{8-10}$

${ }^{a}$ State Key Laboratory of Chemical Resource Engineering, Beijing University of Chemical Technology, Beijing 100029, China.E-mail:wuyx@mail.buct.edu.cn

${ }^{b}$ Department of Chemical Engineering and Biotechnology, Peterhouse, University of Cambridge, Trumpington Street, Cambridge, CB2 1RD, UK

${ }^{c}$ Department of Chemical Engineering, Loughborough University, Loughborough, Leicestershire,LE113TU,UK. E-mail:w.lin@lboro.ac.uk and by grafting polymer onto the Nafion membranes. ${ }^{11}$ Among these approaches, incorporating graphene oxide (GO) or modified GO into Nafion membranes was effective in reducing the methanol crossover., ${ }^{\mathbf{9}, 12,13}$ Although the composite Nafion membranes have been shown to reduce methanol crossover, the proton conductivity decreased considerably due to the barrier effect of GO sheets. ${ }^{12,13}$

Anion exchange membranes (AEMs) are widely used for fuel cell, water electrolysis, chlorine-alkali industry and water treatment applications. ${ }^{\mathbf{1 4}, 15}$ In an anion exchange membrane fuel cell, the oxygen reduction reaction is facile in alkaline environments, and the electro-osmotic drag associated with ion transport opposes the crossover of fuel. ${ }^{16}$ Applying the alkaline AEM in the DMFC could reduce the methanol permeability because the anion transport is from the cathode to the anode, opposing the direction of methanol crossover from anode to cathode. ${ }^{17,18}$

Compared with proton exchange membranes, the lower ionic conductivity of AEMs is a drawback for their application in the DMFC because it leads to reduced cell performance. ${ }^{19-21}$ In order to mitigate this problem, two different but complementary approaches have been employed. One is to develop different types of anion exchange membranes, such as functionalized polysulfone, ${ }^{22,23}$ polyetherketone, ${ }^{24,25}$ fluorinated polymers ${ }^{26-28}$ and poly(styrene- $b$-(ethylene-co-butylene)- $b$-styrene) (SEBS). ${ }^{\mathbf{2 9 , 3 0}}$ Another is incorporating graphene or graphene oxide into anion 
exchange membranes, such as alkali doped polyvinyl alcohol/ graphene, ${ }^{31}$ quaternized polybenzimidazole/quaternized $\mathrm{GO}^{32}$ and quaternized polysulfone/quaternized graphenes. ${ }^{33}$ The modification increases the ion conductivity of the membrane, but the latter is still significantly lower than that of Nafion®. Most of the AEMs are based on quaternary ammonium polymers. However, a major challenge in the development of alkaline AEMs is degradation of quaternary ammonium in strong alkaline media since the chemical stability affects the fuel cell lifetime and performance. ${ }^{34}$ It has been reported that cross-linked quaternized or alkaline imidazolium-functionalized polysulfonebased AEMs exhibit good chemical stability. ${ }^{35-37}$

Poly(styrene- $b$-isobutylene- $b$-styrene) (SIBS) is a triblock copolymer and phase-segregated thermoplastic elastomer in which the polystyrene (PS) segments can be functionalized for further applications. SIBS proton exchange membrane modified by sulfonation has exhibited good obstruction ability towards methanol and a high conductivity to protons. ${ }^{34,38}$ As the polyisobutylene (PIB) block cannot be modified, the non-ionic block can act as a barrier to methanol. In addition, SIBS has the ability to form phase segregation micromorphology which may affect the transport properties and subsequently DMFC performance. ${ }^{34,35}$ Therefore SIBS is adopted in the present work as the starting material to prepare AEMs with the purpose of achieving good performance.

In this study, SIBS was firstly functionalized by chloromethylation, then quaternized with $N, N, N^{\prime}, N^{\prime}$-tetramethyl-1,6hexanediamine (TMHDA) to provide quaternary ammonium ion groups and to increase the mechanical strength of the resultant polymer membrane by simultaneous formation of cross-linked structure; the product was named QSIBS. The ionic conductivity and the methanol permeability of QSIBS membrane were determined at different temperatures from 30 to $80{ }^{\circ} \mathrm{C}$. In order to further improve the ionic conductivity, octadecylaminefunctionalized graphene oxide (GOA) and partially quaternized GOA (GOAN), respectively, were introduced into QSIBS. When the GOA content was $c a .0 .50 \mathrm{wt} \%$, the QSIBS/GOA composite membrane exhibited highest ionic conductivity. Moreover, the ionic conductivity of QSIBS/GOAN-0.50 wt\% was actually higher than that of QSIBS/GOA-0.50 wt\%, and was comparable with that of Nafion 115 . On the other hand, the methanol permeabilities of both QSIBS/GOA-0.50 wt\% and QSIBS/GOAN-0.50 wt\% composite membranes were much lower than that of Nafion 115.

\section{Experimental}

\section{Materials}

Poly(styrene- $b$-isobutylene- $b$-styrene) (SIBS) triblock copolymer with an average number molecular weight $\left(M_{\mathrm{n}}\right)$ of $76000 \mathrm{~g}$ $\mathrm{mol}^{-1}$, polydispersity $\left(M_{\mathrm{w}} / M_{\mathrm{n}}\right)$ of 1.9 and $43 \%$ by weight of styrene units, was synthesized via living cationic polymerization. ${ }^{39,40}$ Graphite powder (ca. $45 \mu \mathrm{m}$, Qingdao Taichang Graphite Processing Plant), octadecylamine (A.R., Alfa Aesar), 1,3,5-trioxane (A. R., Alfa Aesar), chlorotrimethylsilane (A.R., Sinopharm Chemical Reagent Co., Ltd), anhydrous tin tetrachloride (A.R., Beijing HWRK Chem. Co. Ltd.), $N, N, N^{\prime}, N^{\prime}-$ tetramethyl-1,6-hexanediamine (TMHDA, A.R., Fluka), chloroform (A.R., Beijing Chemical Works), ethanol (A.R., Beijing Chemical Works), $\mathrm{KMnO}_{4}$ (A. R., Beijing Chemical Works), $\mathrm{NaNO}_{3}$ (A. R., Beijing Chemical Works), $\mathrm{H}_{2} \mathrm{SO}_{4}$ (A. R., Beijing Chemical Works), $\mathrm{H}_{2} \mathrm{O}_{2}$ (A. R., Beijing Chemical Works), $\mathrm{HCl}$ (A. R., Beijing Chemical Works), $\mathrm{BaCl}_{2}$ (A. R., Beijing Chemical Works), benzyl chloride (A. R., Alfa Aesar) and $\mathrm{NaOH}$ (A. R., Beijing Chemical Works) were used as received.

\section{Synthesis of chloromethylated poly(styrene- $b$-isobutylene- $b$ - styrene) (CSIBS)}

Chloromethylated SIBS (CSIBS) was synthesized by chloromethylation of SIBS according to the literature. ${ }^{41-43}$ SIBS $(5.0 \mathrm{~g})$, trioxane $(6.2 \mathrm{~g})$ and chlorotrimethylsilane $(26.3 \mathrm{~mL})$ were dissolved in chloroform $(300 \mathrm{~mL})$ in a flask at $25^{\circ} \mathrm{C}$; anhydrous tin tetrachloride $(4.5 \mathrm{~mL})$ was added to the above mixture at $0{ }^{\circ} \mathrm{C}$ under stirring for $30 \mathrm{~min}$ and then at room temperature $\left(25^{\circ} \mathrm{C}\right)$ for another $8 \mathrm{~h}$. The reaction solution was precipitated by adding ethanol. The product was purified by dissolutionprecipitation in chloroform-ethanol, and dried for $24 \mathrm{~h}$ in a vacuum oven at room temperature.

\section{Preparation of cross-linked QSIBS anion exchange membrane}

The quaternization was carried out by adding TMHDA to the CSIBS $(1.0 \mathrm{~g})$ solution in chloroform $(20 \mathrm{~mL})$ with $-\mathrm{N}\left(\mathrm{CH}_{3}\right)_{2} /-$ $\mathrm{CH}_{2} \mathrm{Cl}=10$ (molar ratio) at $0{ }^{\circ} \mathrm{C}$ under stirring for $90 \mathrm{~s}$ and then poured on glass plates for reaction and solvent evaporation at $25{ }^{\circ} \mathrm{C}$ for $24 \mathrm{~h}$. Then, the formed membrane was peeled off and put in a vacuum oven at $60{ }^{\circ} \mathrm{C}$ for $24 \mathrm{~h}$ to remove the residual solvent. The dried membranes were immersed in $2 \mathrm{M} \mathrm{NaOH}$ solution to complete anion exchange from $\mathrm{Cl}^{-}$to $\mathrm{OH}^{-}$at $25{ }^{\circ} \mathrm{C}$ for $24 \mathrm{~h}$. After being rinsed carefully with deionized water, the cross-linked quaternized SIBS (QSIBS) AEMs were immersed in deionized water before testing.

\section{Synthesis of octadecylamine graphene oxide (GOA)}

The preparation of graphene oxide (GO) is based on a modified Hummers' method. ${ }^{44} 3 \mathrm{~g}$ of $\mathrm{NaNO}_{3}$ was added to $69 \mathrm{~mL}$ of cold $\left(0{ }^{\circ} \mathrm{C}\right)$ concentrated $\mathrm{H}_{2} \mathrm{SO}_{4}$. After the $\mathrm{NaNO}_{3}$ had dissolved, $3 \mathrm{~g}$ of natural graphite was added to this solution. Then, $3 \mathrm{~g}$ of $\mathrm{KMnO}_{4}$ was added to the solution, which was kept below $10^{\circ} \mathrm{C}$ and then stirred at $35^{\circ} \mathrm{C}$ for $30 \mathrm{~min} .138 \mathrm{~mL}$ of deionized water was added and the mixture was maintained at $98{ }^{\circ} \mathrm{C}$ for $15 \mathrm{~min}$. The reaction was terminated by adding deionized water $(420 \mathrm{~mL})$ and $30 \% \mathrm{H}_{2} \mathrm{O}_{2}$ solution $(30 \mathrm{~mL})$. The product was separated by centrifugation and washed with $5 \mathrm{wt} \% \mathrm{HCl}$ solution until sulfate could not be detected with $\mathrm{BaCl}_{2}$. The product was dried in a vacuum oven at $65{ }^{\circ} \mathrm{C}$ for $24 \mathrm{~h}$.

GO $(0.6 \mathrm{~g})$ and deionized water $(300 \mathrm{~mL})$ were added to a three-neck round-bottom flask. The octadecylamine in ethanol $\left(0.01 \mathrm{~g} \mathrm{~mL}^{-1}\right)$ solution was slowly dropped into the $\mathrm{GO} /$ $\mathrm{H}_{2} \mathrm{O}$ suspension. The mixture was refluxed at $95{ }^{\circ} \mathrm{C}$ for $12 \mathrm{~h}$, and filtered at room temperature. The powder collected was washed with ethanol to remove octadecylamine and then dried for $24 \mathrm{~h}$ under vacuum at $65{ }^{\circ} \mathrm{C}$. The size of the GOA produced was 1$3 \mu \mathrm{m}$. 


\section{Synthesis of quaternized graphene oxide (GOAN)}

Octadecylamine-functionalized graphene oxide (GOA) was synthesized by a previously published method. ${ }^{45}$ Octadecylamine $(0.3 \mathrm{~g})$ and $N, N$-dimethyl-1,3-propanediamine $(47 \mu \mathrm{L})(3: 1$, molar ratio) were dissolved in $30 \mathrm{~mL}$ ethanol, and the solution was dropped into a $\mathrm{GO} /$ deionized water $\left(0.002 \mathrm{~g} \mathrm{~mL}^{-1}\right)$ dispersion. The mixture was refluxed under stirring at $90^{\circ} \mathrm{C}$ for $12 \mathrm{~h}$ and filtered. The powder collected was washed with ethanol. The product was reacted with $30 \mathrm{~mL}$ benzyl chloride at $60{ }^{\circ} \mathrm{C}$ for $12 \mathrm{~h}$. The solid product was removed by filtration and washed with ethanol to remove the adsorbed reagent and then dried for $24 \mathrm{~h}$ under vacuum at $65{ }^{\circ} \mathrm{C}$. The size of the GOAN produced was $1-3 \mu \mathrm{m}$.

\section{Preparation of cross-linked QSIBS/GOA and QSIBS/GOAN hybrid composite anion exchange membrane}

GOA (5 mg) was dispersed in chloroform $(10 \mathrm{~mL})$ by ultrasonication. The resulting suspension was mixed with CSIBS/ chloroform solution $\left(0.1 \mathrm{~g} \mathrm{~mL}^{-1}\right)$. Then TMHDA was added to the mixture and stirred for $90 \mathrm{~s}$ at $0{ }^{\circ} \mathrm{C}$. GOAN (5 mg) was dispersed in chloroform $(10 \mathrm{~mL})$ by ultrasonication. The resulting suspension was mixed with CSIBS/chloroform solution $\left(0.1 \mathrm{~g} \mathrm{~mL}^{-1}\right)$. Then TMHDA was added to the mixture and stirred for $90 \mathrm{~s}$ at $0{ }^{\circ} \mathrm{C}$.

The above mixtures were poured onto glass plates at $25{ }^{\circ} \mathrm{C}$ and the solvent allowed to evaporate for $24 \mathrm{~h}$. The membrane formed was peeled off and dried at $60{ }^{\circ} \mathrm{C}$ to remove the residual solvent. The dried QSIBS/GOA and QSIBS/GOAN hybrid composite membranes were immersed in $\mathrm{NaOH}$ solution for 24 $\mathrm{h}$ to allow anion exchange from $\mathrm{Cl}^{-}$to $\mathrm{OH}^{-}$to complete.

\section{Characterization}

Determination of degree of functionalization of $-\mathrm{CH}_{2} \mathrm{Cl}$ groups in CSIBS by ${ }^{\mathbf{1}} \mathbf{H}$ NMR. Nuclear magnetic resonance spectroscopy $\left({ }^{1} \mathrm{H}\right.$ NMR) characterization was performed on SIBS/CSIBS copolymers dissolved in $\mathrm{CDCl}_{3}$ using a Bruker AV400 $\mathrm{MHz}$ spectrometer at $25{ }^{\circ} \mathrm{C}$. The degree of chloromethylation $\left(F_{\mathrm{CH}_{2} \mathrm{Cl}}\right)$ in CSIBS copolymers was determined on the basis of integrating characteristic resonances in ${ }^{1} \mathrm{H}$ NMR spectra according to eqn (1).

$$
F_{\mathrm{CH}_{2} \mathrm{Cl}}=\frac{\frac{A_{\mathrm{CH}_{2} \mathrm{Cl}}}{2}}{\frac{A_{\mathrm{CH}_{2} \mathrm{Cl}}}{2}+\frac{A_{\text {phenyl }}-2 A_{\mathrm{CH}_{2} \mathrm{Cl}}}{5}} \times 100 \%
$$

where $A_{\mathrm{CH}_{2} \mathrm{Cl}}$ and $A_{\text {phenyl }}$ are, respectively, the peak areas at $\delta=$ 4.4-4.6 ppm for $-\mathrm{CH}_{2} \mathrm{Cl}$ groups and at $\delta=6.3-7.2 \mathrm{ppm}$ for phenyl groups in CSIBS.

Determination of degree of reaction of functional quaternary ammonium groups in QSIBS/GOA hybrid composite anion exchange membrane. In accordance with the oxygen flask combustion titration method, ${ }^{46}$ the membrane sample was wrapped in paper, and was clamped to a dry platinum plate. The platinum plate was fixed under the glass stopper of the oxygen flask. Oxygen was introduced into the flask, and then the paper was burnt in the oxygen flask. The hydrogen chloride produced was absorbed by $2 \mathrm{M} \quad \mathrm{NaOH}$ aqueous solution.
Diphenylcarbazone was used as the indicator and mercuric nitrate as the standard solution to titrate chlorine anions in the solution. The degree of reaction of CSIBS and TMHDA can be calculated according to eqn (2).

$$
F_{\mathrm{N}}=\frac{\frac{C_{\mathrm{St}}}{M_{\mathrm{St}}} \times F_{\mathrm{CH}_{2} \mathrm{Cl}}-\frac{2 C V}{m}}{\frac{C_{\mathrm{St}}}{M_{\mathrm{St}}} \times F_{\mathrm{CH}_{2} \mathrm{Cl}}}
$$

where $C$ is the concentration of mercuric nitrate standard solution, $V$ is the volume of mercuric nitrate standard solution used in titration, $m$ is the weight of the QSIBS membrane, $C_{\mathrm{St}}$ (0.43) is the weight content of PS segments in SIBS, and $M_{\mathrm{St}}$ (104) is the molecular weight of the styrene unit.

\section{Micromorphology of QSIBS/GOA hybrid composite anion exchange membrane}

Transmission electron microscopy (TEM) measurement was performed on a Hitachi $\mathrm{H}-800$ electron microscope operating at an acceleration voltage of $200 \mathrm{kV}$. The membrane samples were immobilized by embedding in epoxy resin and sliced into ultrathin sections at $-60{ }^{\circ} \mathrm{C}$. The ultrathin sample sections for TEM observation were stained with ruthenium tetroxide on a carbon-coated copper grid.

\section{Water uptake and ion exchange capacity}

Water uptake $\left(W_{\mathrm{u}}, \%\right)$ in the QSIBS/GOA membrane was measured by the difference in weight of the membranes before and after immersing in excess deionized water. ${ }^{47,48}$ The weight of the wet membrane $\left(m_{\mathrm{w}}, \mathrm{g}\right)$ was determined after removing excess surface water with a tissue. Then the wet membranes were dried in a vacuum oven at $80{ }^{\circ} \mathrm{C}$ until a constant dry weight $\left(m_{\mathrm{d}}, \mathrm{g}\right)$ was obtained. $W_{\mathrm{u}}$ was determined according to eqn (3).

$$
W_{\mathrm{u}}=\frac{m_{\mathrm{w}}-m_{\mathrm{d}}}{m_{\mathrm{d}}} \times 100 \%
$$

The ion exchange capacity (IEC) of the cross-linked QSIBS/ GOA membranes is defined by the number of moles of cationic groups per unit mass of dry polymer $\left(\mathrm{mmol} \mathrm{g}^{-1}\right)$ that was measured by the classical back-titration method. ${ }^{48,49} \mathrm{~A}$ small sample of the QSIBS membrane was soaked in $30 \mathrm{~mL}$ of $0.01 \mathrm{M} \mathrm{HCl}$ solution for $48 \mathrm{~h}$ to ensure complete equilibration. The IEC was determined from the reduction in acid measured using $0.01 \mathrm{M} \mathrm{NaOH}$ titration according to eqn (4).

$$
\mathrm{IEC}=\frac{\left(V_{\mathrm{HCl}}-V_{\mathrm{NaOH}}\right) \times C_{\mathrm{NaOH}}}{m_{\mathrm{d}}}
$$

where $V_{\mathrm{HCl}}$ is the volume of $\mathrm{HCl}$ solution used for soaking the membrane $(\mathrm{mL}), V_{\mathrm{NaOH}}$ is the volume of $\mathrm{NaOH}$ solution used in titration $(\mathrm{mL})$, and $m_{\mathrm{d}}$ is the mass of the dry QSIBS/GOA membrane $(\mathrm{g})$.

\section{Ionic conductivity}

The ionic conductivity of the membranes in the transverse direction was measured at temperatures ranging from 30 to 80 
${ }^{\circ} \mathrm{C}$ by two-probe AC impedance spectroscopy using the electrochemical apparatus (CS350, CorrTest Instrument, China) over the frequency range $0.1 \mathrm{~Hz}$ to $1 \mathrm{MHz} .^{29,47}$ The membrane was placed in a chamber with deionized water to maintain the relative humidity at $100 \%$ during each experiment. Conductivity $\left(\sigma, \mathrm{S} \mathrm{cm}^{-1}\right)$ was calculated according to eqn (5).

$$
\sigma=\frac{l}{R \times a \times b}
$$

where $l$ is the thickness $(\mathrm{cm})$ of the membrane, $a$ is the width $(\mathrm{cm})$ of the membrane, $b$ is the length $(\mathrm{cm})$ of the membrane, and $R$ is the resistance $(\Omega)$ acquired from a Nyquist plot. The conductivity values tested by the two-probe method are lower than those tested by the four-probe method. It has been reported that the ionic conductivity of Nafion 115 was $2.34 \times 10^{-2}$ $\mathrm{S} \mathrm{cm}^{-1}$ at $30^{\circ} \mathrm{C}$ tested with the two-probe method and ca. $1.09 \times$ $10^{-1} \mathrm{~S} \mathrm{~cm}^{-1}$ at $30^{\circ} \mathrm{C}$ tested with the four-probe method. ${ }^{50,51}$

\section{Methanol permeability}

The methanol permeability of the cross-linked QSIBS membranes was measured at temperatures ranging from 30 to $60{ }^{\circ} \mathrm{C}$ using a diffusion cell. The cell consists of two identical diffusion compartments of approximately $160 \mathrm{~mL}$. The membrane was clamped between the two compartments. One compartment (A) was filled with deionized water $(150 \mathrm{~mL})$. The other one (B) contained the same volume of $2 \mathrm{M}$ methanol solution $(150 \mathrm{~mL})$. The cell was stirred in a water bath at a constant temperature. The methanol concentration with time $(t)$ in compartment A was measured on-line by attenuated total reflectance-Fourier transform infrared (ATR-FTIR) spectroscopy. ${ }^{34}$ Assuming the pseudo-steady-state and the concentration of methanol solution in compartment $\mathrm{B}\left(C_{\mathrm{B}}\right)$ is much greater than the concentration of methanol solution in compartment $\mathrm{A}$ $\left(C_{\mathrm{A}}\right)$, the methanol permeability $P_{\mathrm{m}}\left(\mathrm{cm}^{2} \mathrm{~s}^{-1}\right)$ can be estimated according to eqn (6). ${ }^{20}$

$$
C_{\mathrm{A}}(t)=C_{\mathrm{B}}\left(\frac{A}{l}\right)\left(\frac{P}{V_{\mathrm{A}}}\right) t
$$

where $V_{\mathrm{A}}$ is the volume of the solution in compartment $\mathrm{A}(\mathrm{mL}), l$ is the membrane thickness (cm), and $A$ is the effective area of the membrane $\left(\mathrm{cm}^{2}\right)$.

\section{Chemical stability}

The membrane was immersed in $2 \mathrm{M} \mathrm{NaOH}$ solution at $60{ }^{\circ} \mathrm{C}$ for different times. The chemical stability of QSIBS/GOA membranes was evaluated by testing the ionic conductivity of the same membrane. The $\mathrm{NaOH}$ solution was refreshed every 10 $\mathrm{h}$ for 50 times.

\section{Results and discussion}

SIBS was synthesized via living cationic polymerization in our laboratory and selected as the basic material in this work. SIBS was firstly functionalized by chloromethylation of the phenyl groups in polystyrene segments to prepare chloromethylated SIBS (CSIBS). Then, CSIBS was quaternized and in situ cross- linked with $\quad N, N, N^{\prime}, N^{\prime}$-tetramethyl-1,6-hexanediamine (TMHDA), a quaternization and cross-linking reagent (Scheme 1), to provide quaternary ammonium ion groups; the product was named QSIBS. The mechanical strength of the resultant QSIBS polymer membrane could be improved due to the crosslinked structure.

In order to determine $F_{\mathrm{CH}_{2} \mathrm{Cl}}$, SIBS and CSIBS were characterized by ${ }^{1} \mathrm{H}$ NMR; the corresponding spectra are presented in Fig. 1. It can be seen from Fig. 1 that the characteristic resonance at $\delta=4.5 \mathrm{ppm}$ was assigned to the protons in the $-\mathrm{CH}_{2} \mathrm{Cl}$ groups. $F_{\mathrm{CH}_{2} \mathrm{Cl}}$ was determined to be $30 \%$ on the basis of characteristic resonances according to eqn (1).

In order to investigate the quaternization in the cross-linked QSIBS, the quaternization reaction of CSIBS with TMHDA was performed by FTIR characterization. The FTIR spectra of SIBS, CSIBS and QSIBS/GOA-05 wt\% are presented in Fig. 2. The characteristic absorption at $1265 \mathrm{~cm}^{-1}$ for $\mathrm{C}-\mathrm{Cl}$ wagging vibration $^{52-55}$ appeared after chloromethylation of SIBS, indicating the formation of $-\mathrm{CH}_{2} \mathrm{Cl}$ functional groups in the chloromethylated SIBS (CSIBS) block copolymer. Compared with the FTIR spectrum of CSIBS, the characteristic peak at 1265 $\mathrm{cm}^{-1}$ for $\mathrm{CH}_{2} \mathrm{Cl}$ group was remarkably decreased after quaternization, as shown in FTIR spectra of QSIBS and QSIBS/GOA$0.50 \mathrm{wt} \%$. The result indicates the transformation of $-\mathrm{CH}_{2} \mathrm{Cl}$ to $-\mathrm{N}^{+} \mathrm{R}_{3} \mathrm{Cl}^{-}$via quaternization.

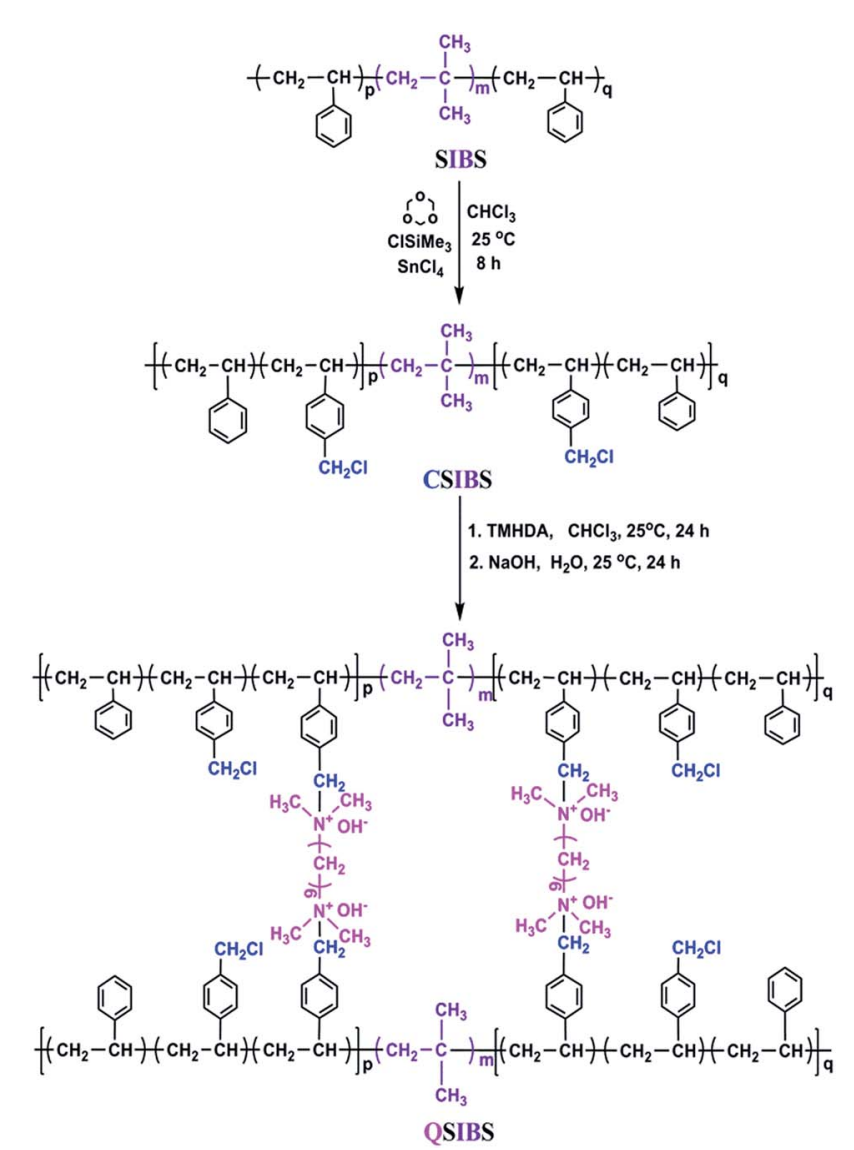

Scheme 1 Synthesis of QSIBS via chloromethylation and quaternization reactions. 

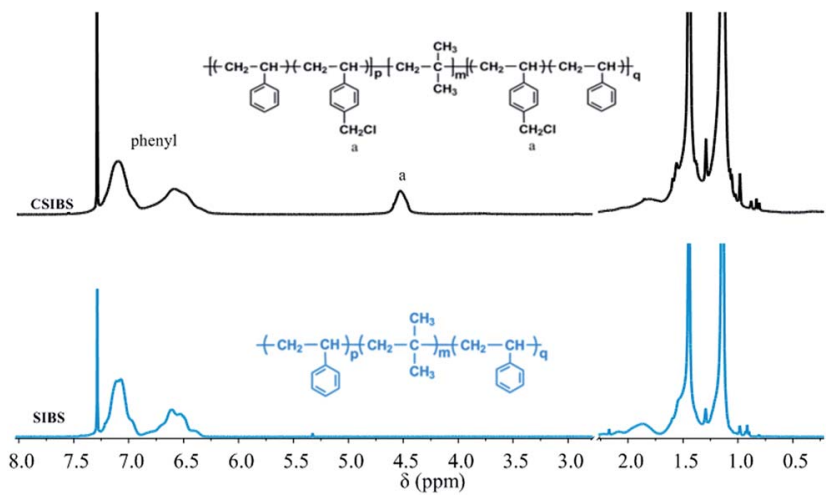

Fig. $1{ }^{1} \mathrm{H}$ NMR spectra for SIBS and CSIBS in $\mathrm{CDCl}_{3}$ at $25^{\circ} \mathrm{C}$.

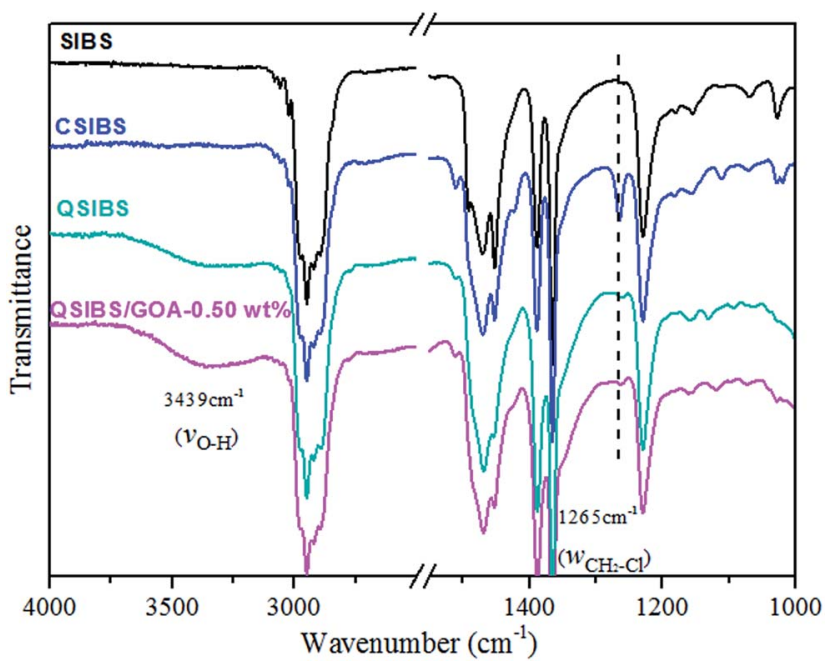

Fig. 2 FTIR spectra of SIBS, CSIBS and QSIBS/GOA-05 wt\%.

Octadecylamine-functionalized graphene oxide (GOA) was introduced into QSIBS because of its better dispersion in chloroform. As it is hydrophilic, GO could not be dispersed in chloroform. After grafting the octadecylamine, GOA was hydrophobic and could be dispersed in chloroform evenly, as shown in Fig. 3. GOA was synthesized via the reaction of GO and octadecylamine in pure water according to a reported method. ${ }^{\mathbf{4 4 , 4 5}}$ It has been reported that the functionalized graphene could provide more interconnected ionic transportation channels along the surface of graphene. ${ }^{33} \mathrm{GO}$ was reacted with octadecylamine and $N, N$-dimethyl-1,3-propanediamine with

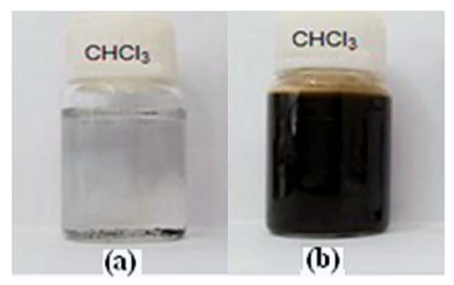

Fig. 3 Photos of GOA suspension in $\mathrm{CHCl}_{3}$ (a) $\mathrm{GO}$; (b) GOA. a molar ratio of $3: 1$ in pure water, and then the product was reacted with benzyl chloride to synthesize a quaternized GOA, named GOAN. The FTIR spectra of GO, GOA and GOAN are presented in Fig. 4. For GOA, the characteristic peaks at 2918 $\mathrm{cm}^{-1}$ and $2848 \mathrm{~cm}^{-1}$ are associated with the stretching vibration of $-\mathrm{CH}_{2}-$ in the octadecyl chain together with the peak at $715 \mathrm{~cm}^{-1}$, implying the existence of the octadecyl chain on GOA. The characteristic peaks at $1570 \mathrm{~cm}^{-1}$ and $1208 \mathrm{~cm}^{-1}$ indicate the formation of $-\mathrm{CH}_{2}-\mathrm{NH}-$ bands due to the reaction between the epoxide group and the amine group. For GOAN, the characteristic peak at $1625 \mathrm{~cm}^{-1}$ implies the existence of a phenyl group in GOAN. It proves that the quaternary ammonium was successfully grafted on the surface of GOAN.

The degree of quaternization, $F_{\mathrm{N}}$, of the cross-linked QSIBS/ GOA composite membranes with different GOA content could be determined by titration of $\mathrm{Cl}^{-}$according to eqn (2). As shown in Fig. 5, $F_{\mathrm{N}}$ of QSIBS/GOA decreased with increasing GOA content in the composite membrane. The sheet structure of GOA or GOAN limited the movement of the molecular chain and decreased the free volume to block the quaternization; therefore the $F_{\mathrm{N}}$ of the composite membranes was lower than that of the pristine QSIBS membrane.

Ionic exchange capacity (IEC) and water uptake $\left(W_{\mathrm{u}}\right)$ have significant effect on the transport behaviour and mechanical properties of anion exchange membranes. Generally, a membrane with higher IEC and $W_{\mathrm{u}}$ can offer more opportunity for the ionic groups $\left(\mathrm{OH}^{-}\right)$to transfer through the membrane, leading to a higher conductivity. However, an excessive water uptake will result in a loss of the mechanical properties and bring about high methanol permeability. ${ }^{29}$ IEC and $W_{\mathrm{u}}$ are the essential parameters for anion exchange membranes to operate in DMFCs. The ionic exchange capacity (IEC) and water uptake $\left(W_{\mathrm{u}}\right)$ of the cross-linked QSIBS/GOA membranes with different GOA content are given in Fig. 6. The IEC of the membranes was dominantly related to $F_{\mathrm{N}}$ in the functionalized copolymers. The $W_{\mathrm{u}}$ of the cross-linked QSIBS/ GOA decreased from $41.5 \%$ to $32.1 \%$ with increasing the GOA content from 0 to $1.0 \mathrm{wt} \%$. Therefore, it can be inferred from Fig. 6 that the incorporation of GOA in QSIBS/GOA membrane impact both IEC and the water uptake.

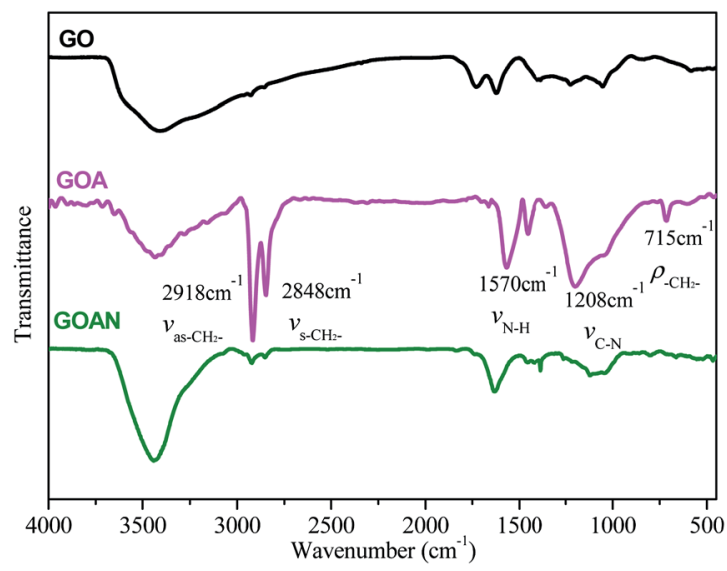

Fig. 4 FTIR spectra of GO, GOA and GOAN. 


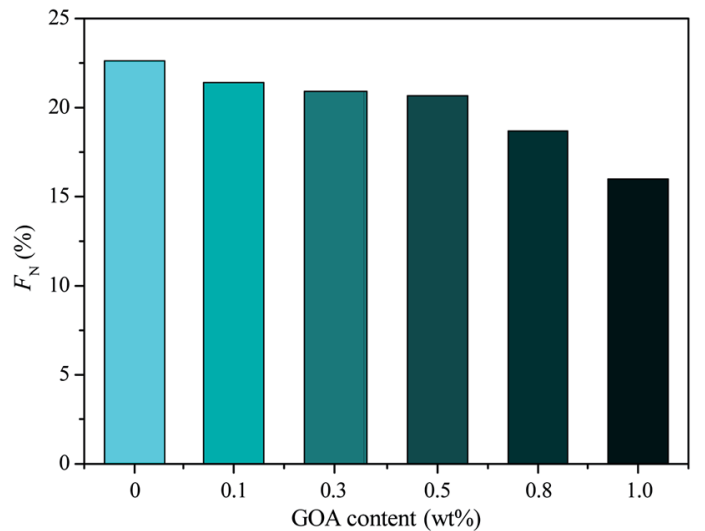

Fig. $5 \quad F_{N}$ of composite membranes with different GOA contents.

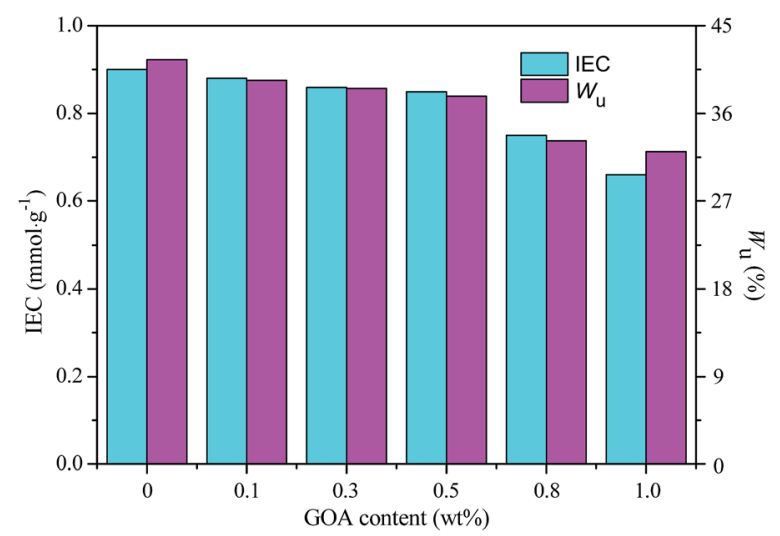

Fig. 6 IEC and water uptake of composite membranes with different GOA content.

The results show that, whilst the ionic conductivity of the QSIBS $\left(1.36 \times 10^{-2} \mathrm{~S} \mathrm{~cm}^{-1}\right)$ was higher than that of recent reported quaternized QSEBS $\left(0.73 \times 10^{-2} \mathrm{~S} \mathrm{~cm}^{-1}\right)^{29,30}$ and other AEMs such as poly(vinyl alcohol) modified quaternized hydroxyethylcellulose ethoxylate (PVA/QHECE) ${ }^{56}$ and quaternized poly(styrene-co-vinylbenzyl chloride), ${ }^{52}$ it is in fact still much lower than that of Nafion $115\left(2.65 \times 10^{-2} \mathrm{~S} \mathrm{~cm}^{-1}\right)$.

In order to further improve the conductivity, octadecylamine-functionalized graphene oxide (GOA) was introduced into QSIBS. The effect of GOA content on the ion transport properties of cross-linked QSIBS/GOA composite membranes was investigated at various temperatures from 30 ${ }^{\circ} \mathrm{C}$ to $80{ }^{\circ} \mathrm{C}$, as shown in Fig. 7(a). All samples with various GOA contents from 0 to $1.00 \mathrm{wt} \%$ exhibit an increasing conductivity with an increase in temperature, implying the mobility of both the ion and the polymer chains increased, resulting in an increase in ionic conductivity. For example, when the GOA content was $c a$. $0.50 \mathrm{wt} \%$, the hydroxide ion conductivity of the QSIBS/GOA increased from $1.40 \times 10^{-2}$ at $30^{\circ} \mathrm{C}$ to $1.88 \times 10^{-2} \mathrm{~S}$ $\mathrm{cm}^{-1}$ at $60{ }^{\circ} \mathrm{C}$ and $2.10 \times 10^{-2}$ at $80^{\circ} \mathrm{C}$. On the other hand, the ionic conductivity became lower than that of pristine QSIBS membranes when GOA content exceeded $0.60 \mathrm{wt} \%$. When the GOA content was increased to $1.00 \mathrm{wt} \%$, the ionic conductivity
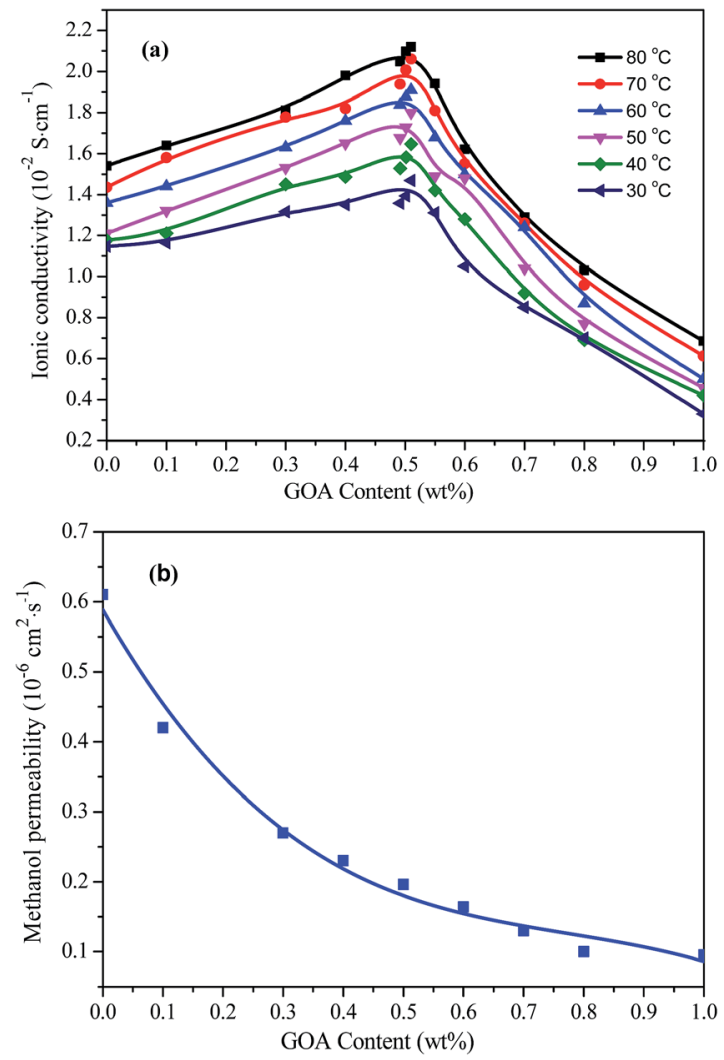

Fig. 7 (a) lonic conductivity of QSIBS/GOA membranes with different GOA contents at different temperatures in pure water. (b) Methanol permeability of QSIBS/GOA in $2 \mathrm{M}$ methanol aqueous solution at $60^{\circ} \mathrm{C}$.

decreased to $0.42 \times 10^{-2} \mathrm{~S} \mathrm{~cm}^{-1}$. In other words, the ionic conductivity of the composite membranes increased to $138 \%$ of that of pristine QSIBS when GOA loading increased up to 0.50 $\mathrm{wt} \%$ and then decreased with the further increase in GOA loading, reducing to $37 \%$ with $1.00 \mathrm{wt} \%$ loading. This observation may be attributed to the fact that the "barrier effect" starts to predominate when the aggregation of the GOA within the composite membranes takes place as the content of GOA reaches beyond $0.50 \mathrm{wt} \%$. On the other hand, it can be seen from Fig. 7(b) that the incorporation of GOA into the composite membranes did inhibit methanol crossover, e.g., at only 0.50 $\mathrm{wt} \%$ of GOA loading the value of methanol permeability decreased to $32.1 \%$ of that for pristine QSIBS, thanks to the increased tortuosity and the barrier effect. ${ }^{12,13,31}$

Photos and SEM images of Nafion 115, QSIBS/GOA-0 and QSIBS/GOA-0.50 wt\% are displayed in Fig. 8. It can be seen clearly that, as the GOA content increases from $0 \mathrm{wt} \%$ to 0.50 $\mathrm{wt} \%$, the flexible composite membranes change from colourless transparent to light grey in colour; all the pristine QSIBS membrane and the GOA doped composite membranes exhibited a smooth surface without any defects that is as good as Nafion 115 commercial membrane.

TEM images of QSIBS/GOA-0, QSIBS/GOA-0.30 wt\%, QSIBS/ GOA-0.50 wt $\%$ and QSIBS/GOA-0.80 wt $\%$ membranes are shown in Fig. 9. The bright domains correspond to the 

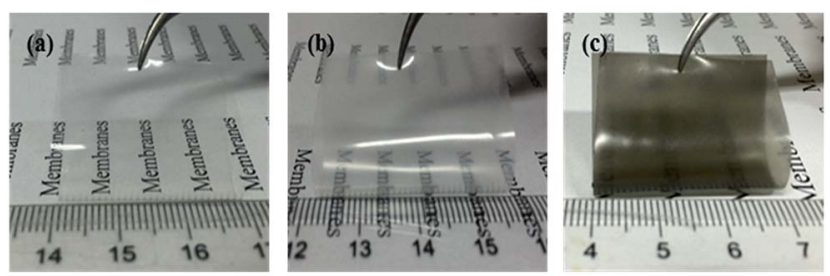

(a')

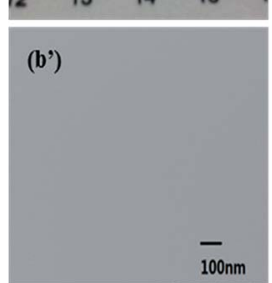

(c')

Fig. 8 Photos and SEM images of the membranes. (a) and (a'): Nafion 115; (b) and (b'): QSIBS/GOA-0; (c) and ( $\left.c^{\prime}\right)$ : QSIBS/GOA-0.50 wt\%.

unstained polyisobutylene phase, and the dark domains are the stained polystyrene phase. The dark regions are the stained hydrophilic domains, which most likely correspond to the quaternary ammonium ion clusters, and the white regions are attributed to the hydrophobic domains within the membranes. Additionally, the TEM image (Fig. 9(c)) of QSIBS/GOA-0.50 wt\% composite membrane clearly shows GOA sheets. The good dispersion and large aspect ratio of the graphene nanosheets resulted in favourable ion transfer across the QSIBS/GOA interface, but unfavourable methanol permeation through the membrane because of the enhancement of tortuosity in the composite membrane. ${ }^{57-59}$ With a higher GOA content, some agglomerates of GOA appeared in the QSIBS/GOA-0.80 wt\% composite membrane, which might be attributed to the higher density of graphene loading promoting strong van der Waals interactions between nanolayers, thus increasing the probability of the graphene nanolayers overlapping in the confined space.
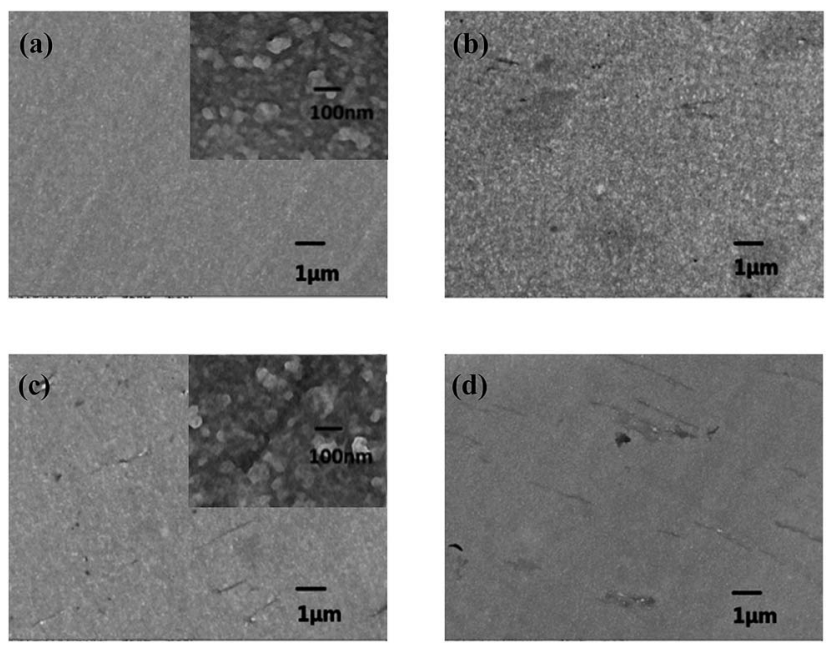

Fig. 9 TEM images of the membranes. (a) QSIBS/GOA-0, (b) QSIBS/ GOA-0.30 wt\%, (c) QSIBS/GOA-0.50 wt\% and (d) QSIBS/GOA$0.80 \mathrm{wt} \%$.

It has been reported that the functionalized graphene could provide more interconnected ionic transportation channels along the surface of graphene. ${ }^{33} \mathrm{GO}$ was reacted with octadecylamine and $N, N$-dimethyl-1,3-propanediamine with molar ratio of $3: 1$ in pure water, and then the product was reacted with benzyl chloride to synthesize a quaternized GOA, named GOAN. In order to further increase the ionic conductivity of the composite membrane, $0.50 \mathrm{wt} \%$ of GOAN was introduced into QSIBS. Thus the QSIBS/GOAN-0.50 wt $\%$ composite membrane was prepared by incorporating QSIBS with GOAN at $0.50 \mathrm{wt} \%$ loading. As shown in Fig. 10, the ionic conductivity of QSIBS/ GOAN-0.50 wt\% $\left(1.95 \times 10^{-2} \mathrm{~S} \mathrm{~cm}^{-1}\right.$ at $\left.60{ }^{\circ} \mathrm{C}\right)$ is actually slightly higher than that of QSIBS/GOA-0.50 wt\% $\left(1.88 \times 10^{-2} \mathrm{~S}\right.$ $\mathrm{cm}^{-1}$ at $\left.60^{\circ} \mathrm{C}\right)$, and is comparable to that of Nafion $115(2.65 \times$ $10^{-2} \mathrm{~S} \mathrm{~cm}^{-1}$ at $\left.60{ }^{\circ} \mathrm{C}\right)$. On the other hand, the methanol permeabilities of both QSIBS/GOA-0.50 wt\% and QSIBS/GOAN$0.50 \mathrm{wt} \%$ composite membranes are much lower than that of Nafion 115, because of the barrier effect. In general, membranes with higher ionic conductivity and lower methanol permeability are more suitable for DMFC application. The selectivity, which is defined as the ratio of ionic conductivity to methanol permeability, has been used as an indicator to evaluate the suitability of a given membrane for DMFC application. ${ }^{\mathbf{1 2 , 1 3 , 6 0}}$ As shown in Fig. 10, the QSIBS/GOAN-0.50 wt\% composite membrane has the highest selectivity, which is about 12 times higher than that of the Nafion 115 membrane. The result may be attributed to two factors: one is the barrier effect of GOAN sheets, which is unfavourable for methanol crossover; and the other is the presence of the hydrophilic groups in the incorporated GOAN, which is favourable for ionic transport. Therefore, QSIBS/GOAN-0.50 wt\% composite membrane could be considered a promising candidate for potential application in DMFCs.

The chemical stability of the anion exchange membranes could strongly affect the ionic transport and the overall alkaline fuel cell performances. The chemical stability of the QSIBS, QSIBS/GOA-0.50 wt\% and QSIBS/GOAN-0.50 wt\% membranes in alkaline media was tested and the main data are shown in Fig. 11. It can be seen that after immersion in $2 \mathrm{M} \mathrm{NaOH}$ solution at $60^{\circ} \mathrm{C}$, the $\mathrm{OH}^{-}$conductivity of the QSIBS membrane

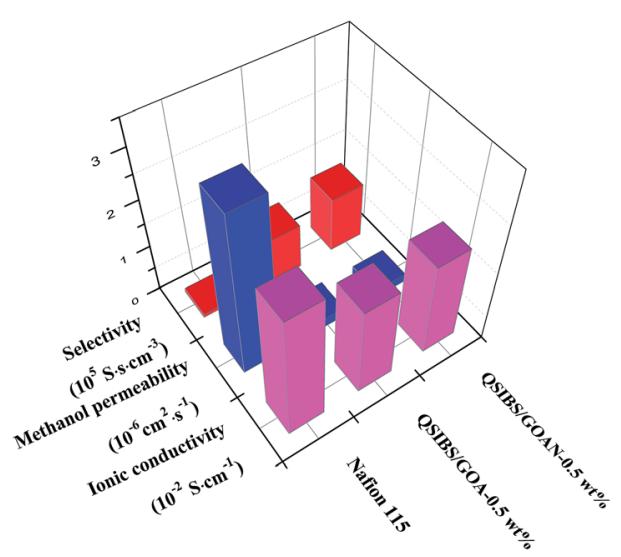

Fig. 10 Comparison of the ionic conductivity, methanol permeability and selectivity of Nafion 115, QSIBS/GOA-0.50 wt\% and QSIBS/GOAN0.50 wt\% membranes. 


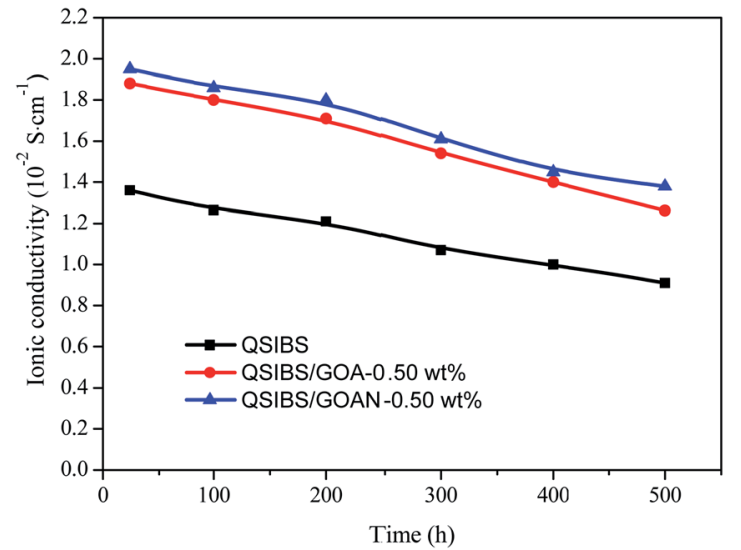

Fig. 11 Comparison of the ionic conductivity of QSIBS, QSIBS/GOA0.50 wt $\%$ and QSIBS/GOAN-0.50 wt $\%$ membranes after immersion in $2 \mathrm{M} \mathrm{NaOH}$ solution for different time at $60^{\circ} \mathrm{C}$.

decreased from $1.36 \times 10^{-2}$ to $0.91 \times 10^{-2} \mathrm{~S} \mathrm{~cm}^{-1}$ after $500 \mathrm{~h}$. The QSIBS/GOAN-0.50 wt\% composite membrane showed better chemical stability under the same experimental conditions, and about $70.8 \%$ of its initial conductivity remained after 500 h. Compared with the chemical stability of some other AEMs reported recently, such as imidazolium-functionalized poly(arylene ether sulfone) (where about $83 \%$ of the initial conductivity remained after $168 \mathrm{~h}$ in $2 \mathrm{M} \mathrm{NaOH}$ solution at 60 $\left.{ }^{\circ} \mathrm{C}\right),{ }^{61}$ and poly(VBC-co-BMA-co-HFMA) (PVBH) (where about $71 \%$ conductivity remained after $120 \mathrm{~h}$ in $2 \mathrm{M} \mathrm{NaOH}$ solution at $\left.60{ }^{\circ} \mathrm{C}\right),{ }^{47}$ the QSIBS-based composite membranes have better chemical stability in alkaline solution at $60^{\circ} \mathrm{C}$.

It is worth mentioning that the chemical stability of quaternary ammonium-functionalized AEMs is always a concern, because these AEMs have a tendency to disintegrate in alkaline solution, due to the displacement of the ammonium group by the anions via a direct nucleophilic displacement and/ or Hofmann elimination reaction when $\beta$-hydrogen atoms are present. ${ }^{29}$ The sheet structure of GOA and GOAN limited the movement of the molecular chain and decreased the free volume to block the nucleophilic displacement of $\mathrm{OH}^{-}$; therefore the chemical stability of the composite membranes is better than that of the pristine QSIBS membrane.

\section{Conclusions}

In conclusion, a quaternized poly(styrene- $b$-isobutylene- $b$ styrene)/graphene oxide composite anion exchange membrane has been prepared via intercalation of organo-modified graphene oxide, and characterized as a promising anion exchange membrane for direct alkaline methanol fuel cell application. Compared with the Nafion ${ }^{\circledR}$ membrane, the new anion exchange membranes show comparable ionic conductivity but much lower methanol permeability. The promising performance is attributed to two factors: one is the barrier effect of the quaternized octadecylamine-functionalized graphene oxide sheets, which is unfavourable for methanol crossover; and the other is the presence of interconnected ionic transportation channels between the incorporated modified graphene oxide and polymer, which is favourable for ionic transport.

\section{Acknowledgements}

The authors acknowledge the financial support from the National Natural Science Foundation of China (51221002), China Petroleum \& Chemical Corporation (Sinopec, 215036) and EPSRC (EP/I013229/1), as part of the RCUK Energy Programme.

\section{Notes and references}

1 P. Joghee, J. N. Malik, S. Pylypenko and R. O'Hayre, MRS Energy \& Sustainability -A Review Journal, 2015, 2, 1-31.

2 F. Robert, Science, 2002, 296, 1222-1224.

3 K. A. Mauritz and R. B. Moore, Chem. Rev., 2004, 104, 45354585.

4 A. Kraytsberg and Y. Ein-Eli, Energy Fuels, 2014, 28, 73037330 .

5 H. W. Zhang, H. P. Huang and P. K. Shen, Int. J. Hydrogen Energy, 2012, 37, 6875-6879.

6 I. T. Kim, J. Choi and S. C. Kim, J. Membr. Sci., 2007, 300, 2835.

7 H. L. Lin and S. H. Wang, J. Membr. Sci., 2014, 452, 253-262.

8 H. S. Thiam, W. R. W. Daud, S. K. Kamarudin, A. B. Mohamad, A. A. H. Kadhum, K. S. Loh and E. H. Majlan, Int. J. Hydrogen Energy, 2013, 38, 9474-9483.

9 H. C. Chien, L. D. Tsai, C. P. Huang, C. Y. Kang, J. N. Lin and F. C. Chang, Int. J. Hydrogen Energy, 2013, 38, 13792-13801.

10 M. M. Hasani-Sadrabadi, E. Dashtimoghadam, F. S. Majedi, S. M. Wu, A. Bertsch, H. Moaddelc and P. Renaud, RSC Adv., 2013, 3, 7337-7346.

11 B. Bae, H. Y. Ha and D. Kim, J. Membr. Sci., 2006, 276, 51-58. 12 L. S. Wang, A. N. Lai, C. X. Lin, Q. G. Zhang, A. M. Zhu and Q. L. Liu, J. Membr. Sci., 2015, 492, 58-66.

13 B. G. Choi, Y. S. Huh, Y. C. Park, D. H. Jung, W. H. Hong and H. S. Park, Carbon, 2012, 50, 5395-5402.

14 H. Strathmann, A. Grabowski and G. Eigenberger, Ind. Eng. Chem. Res., 2013, 52, 10364-10379.

15 J. R. Varcoe, P. Atanassov, D. R. Dekel, A. M. Herring, M. A. Hickner, P. A. Kohl, A. R. Kucernak, W. E. Mustain, K. Nijmeijer, K. Scott, T. Xu and L. Zhuang, Energy Environ. Sci., 2014, 7, 3135-3191.

16 J. R. Varcoe and R. C. T. Slade, Fuel Cells, 2005, 5, 187-200. 17 Y. Xiong, Q. L. Liu, A. M. Zhu, S. M. Huang and Q. H. Zeng, J. Power Sources, 2009, 186, 328-333.

18 Y. Wang, L. Li, L. Hu, L. Zhuang, J. T. Lu and B. Q. Xu, Electrochem. Commun., 2003, 5, 662-666.

19 Y. Xiong, Q. L. Liu and Q. H. Zeng, J. Power Sources, 2009, 193, 541-546.

20 L. Wu, T. W. Xu, D. Wu and X. Zheng, J. Membr. Sci., 2008, 310, 577-585.

21 L. H. Jiang, X. C. Lin, R. Jin, C. R. Li, L. Wu and T. W. Xu, Chin. J. Chem., 2012, 30, 2241-2246.

22 X. M. Yan, G. H. He, S. Gu, X. M. Wu, L. G. Du and Y. D. Wang, Int. J. Hydrogen Energy, 2012, 37, 5216-5224. 
23 N. W. Li, Q. Zhang, C. Y. Wang, Y. M. Lee and M. D. Guiver, Macromolecules, 2012, 45, 2411-2419.

24 H. W. Zhang and Z. T. Zhou, J. Appl. Polym. Sci., 2008, 110, 1756-1762.

25 Y. Xiong, Q. L. Liu and Q. H. Zeng, J. Power Sources, 2009, 193, 541-546.

26 R. C. T. Slade and J. R. Varcoe, Solid State Ionics, 2005, 176, 585-611.

27 J. R. Varcoe, R. C. T. Slade, E. L. H. Yee, S. D. Poynton, D. J. Driscoll and D. C. Apperley, Chem. Mater., 2007, 19, 2686-2693.

28 B. Tian, C. W. Yan and F. H. Wang, Chin. J. Polym. Sci., 2007, 22, 505-510.

29 Q. H. Zeng, Q. L. Liu, B. Ian, A. M. Zhu, Y. Xiong and X. P. Tu, J. Membr. Sci., 2010, 349, 237-243.

30 R. Vinodh, A. Ilakkiya, S. Elamathi and D. Sangeetha, Mater. Sci. Eng., B, 2010, 167, 43-50.

31 Y. S. Ye, M. Y. Cheng, X. L. Xie, J. Rick, Y. J. Huang, F. C. Chang and B. J. Hwang, J. Power Sources, 2013, 239, 424-432.

32 H. Zarrin, J. Fu, G. P. Jiang, S. Yoo, J. Lenos, M. Fowler and Z. W. Chen, ACS Nano, 2015, 9, 2028-2037.

33 L. D. Liu, C. Y. Tong, Y. He, Y. X. Zhao and C. L. Lü, J. Membr. Sci., 2015, 487, 99-108.

34 Y. A. Elabd, E. Napadensky, J. M. Sloan, D. M. Crawford and C. W. Walker, J. Membr. Sci., 2003, 217, 227-242.

35 X. Y. Lu, W. P. Steckle and R. A. Weiss, Macromolecules, 1993, 26, 5876-5884.

36 S. Maurya, S. H. Shin, M. K. Kim, S. H. Yun and S. H. Moon, J. Membr. Sci., 2013, 443, 28-35.

37 A. H. N. Rao, S. Y. Nam and T. H. Kim, $R S C A d v ., 2016,6$, 16168-16176.

38 Y. A. Elabd, E. Napadensky, C. W. Walker and K. I. Winey, Macromolecules, 2006, 39, 399-407.

39 R. F. Storey, D. W. Baugh and K. R. Choate, Polymer, 1999, 40, 3083-3090.

40 P. F. Yan, A. R. Guo, Q. Liu and Y. X. Wu, J. Polym. Sci., Part A: Polym. Chem., 2012, 50, 3383-3392.

41 S. Itsuno, K. Uchikoshi and K. Ito, J. Am. Chem. Soc., 1990, 112, 8187-8188.

42 M. S. Niu, R. W. Xu, P. Dai and Y. X. Wu, Polymer, 2013, 54, 2658-2667.

43 M. S. Niu, T. Lin, R. W. Xu, X. Y. Gu and Y. X. Wu, J. Appl. Polym. Sci., 2013, 129, 1833-1844.
44 W. S. Hummers and R. E. Offeman, J. Am. Chem. Soc., 1958, 80, 1339.

45 W. Li, X. Z. Tang, H. B. Zhang, Z. G. Jiang, Z. Z. Yu, X. S. Du and Y. W. Mai, Carbon, 2011, 49, 4724-4730.

$46 \mathrm{~W}$. J. Kirsten, Ulteramicro determination of chlorine, bromine and iodine. Organic elemental analysis: ultramicro, micro, and trace methods, Academic Press, New York, 1983, pp. 113-120.

47 Y. M. Zhang, J. Fang, Y. B. Wu, H. K. Xu, X. J. Chi, W. Li, Y. X. Yang, G. Yan and Y. Z. Zhuang, J. Colloid Interface Sci., 2012, 381, 59-66.

48 S. Xu, G. Zhang, Y. Zhang, C. J. Zhao, W. J. Ma, H. C. Sun, N. Zhang, L. Y. Zhang, H. Jiang and H. Na, J. Power Sources, 2012, 209, 228-235.

49 Y. Luo, J. Guo, C. Wang and D. Chu, J. Power Sources, 2010, 195, 3765-3771.

50 Q. H. Zeng, Q. L. Liu, I. Broadwell and A. M. Zhu, J. Membr. Sci., 2010, 349, 237-243.

51 S. Kang, D. Jung, J. Shin, S. Lim, S. K. Kim, Y. Shul and D. H. Peck, J. Membr. Sci., 2013, 447, 36-42.

52 S. Vengatesan, S. Santhi, S. Jeevanantham and G. Sozhan, J. Power Sources, 2015, 284, 361-368.

53 J. Hu, Y. D. Meng, C. X. Zhang and S. D. Fang, Thin Solid Films, 2011, 519, 2155-2162.

54 R. Espiritu, M. Mamlouk and K. Scott, Int. J. Hydrogen Energy, 2016, 41, 1120-1133.

55 S. Vengatesan, S. Santhi, G. Sozhan, S. Ravichandran, D. J. Davidson and S. Vasudevan, RSC Adv., 2015, 5, 2736527371.

56 T. C. Zhou, J. Zhang, J. L. Qiao, L. L. Liu, G. P. Jiang, J. Zhang and Y. Y. Liu, J. Power Sources, 2013, 227, 291-299.

57 Z. Q. Jiang, X. S. Zhao, Y. Z. Fu and A. Manthiram, J. Mater. Chem., 2012, 22, 24862-24869.

58 C. Y. Tseng, Y. S. Ye, M. Y. Cheng, K. Y. Kao, W. C. Shen, J. Rick, J. C. Chen and B. J. Hwang, Adv. Energy Mater., 2011, 1, 1220-1224.

59 B. G. Choi, J. Hong, Y. C. Park, D. H. Jung, W. H. Hong, P. T. Hammond and H. Park, ACS Nano, 2011, 5, 5167-5174.

60 K. Dutta, S. Das, P. Kumar and P. P. Kundu, Appl. Energy, 2014, 118, 183-191.

61 A. H. N. Rao, R. L. Thankamony, H. J. Kim, S. Nam and T. H. Kim, Polymer, 2013, 54, 111-119. 